
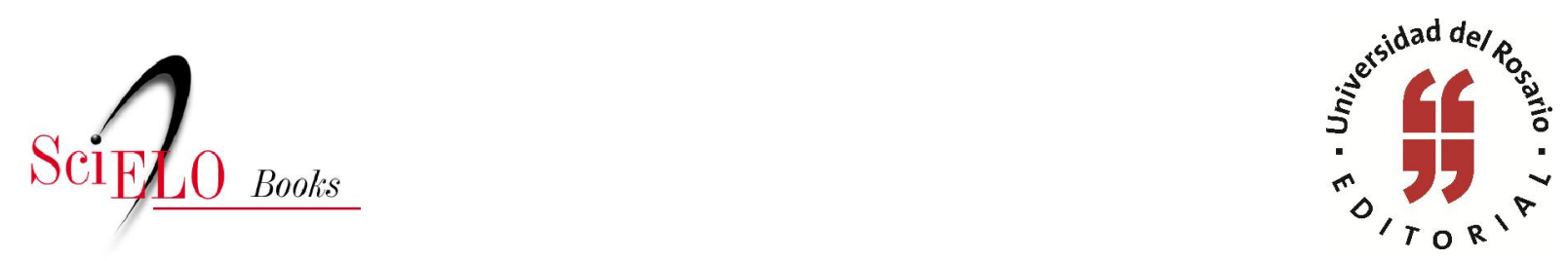

\title{
Conclusiones
}

El poder de la narrativa

Sebastián Quiroga Cubides

SciELO Books / SciELO Livros / SciELO Libros

QUIROGA CUBIDES, S. Conclusiones - El poder de la narrativa. In: Reinventar un héroe. Narrativas sobre los soldados rasos de la guerra de Corea [online]. Bogotá: Editorial Universidad del Rosario, Escuela de ciencias humanas, 2015. Opera prima collection, pp. 197-203. ISBN 978-958-738-593-9. Available from: doi: 10.7476/9789587385939. Also available in ePUB from: http://books.scielo.org/id/s2rwx/epub/quiroga-9789587385939.epub.

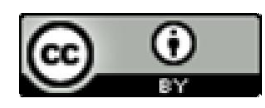

All the contents of this work, except where otherwise noted, is licensed under a Creative Commons Attribution 4.0 International license.

Todo o conteúdo deste trabalho, exceto quando houver ressalva, é publicado sob a licença Creative Commons Atribição 4.0.

Todo el contenido de esta obra, excepto donde se indique lo contrario, está bajo licencia de la licencia $\underline{\text { Creative Commons }}$ $\underline{\text { Reconocimento 4.0. }}$. 


\section{Conclusiones El poder de la narrativa}

El rol del soldado, como aquí se analizó, es variable y contingente. Se ha ajustado según el narrador y el momento histórico desde el cual se habla. Esto nos enseña una cosa sobre la historia: no es estática ni inmutable, se encuentra en constante reconstrucción. Es producida más allá del gremio profesional de historiadores o de la memoria que busquen imponer los gobiernos. Desde una exitosa obra de teatro, hasta un monumento arrinconado, desde una provocativa novela hasta una tesis de grado, la historia está viva en la sociedad. En este proceso de revisión de la construcción de la guerra de Corea, apreciamos cómo el soldado pasó a convertirse de objeto a sujeto de la historia, y las implicaciones que tiene ello en el proceso de producción y consolidación de la historia.

En los años cincuenta fue el nacimiento de la narrativa: el soldado pasó de ser un actor figurante en los diarios durante los entrenamientos del batallón, que desconocía las dimensiones de la guerra, a un héroe cuando estaba en el campo de batalla. El presidente Laureano Gómez lo representó como la máxima figura del ideal nacional, cristiano y heredero de la hispanidad. El discurso posterior de Rojas Pinilla fue más incluyente, pero de igual manera mostraba al soldado 
como el defensor de un modelo de sociedad ante el comunismo. La imagen del Ejército comenzó a desdibujarse por su implicación en la Violencia, y en el caso de los soldados de Corea en la masacre estudiantil de junio de 1954. A partir de allí, el lenguaje heroico permanecería en los oficiales que participaron en la guerra, a través de sus memorias y los diferentes textos y discursos que difundieron. Por un lado, el papel del soldado estaba en auge, dentro de la memoria de estos oficiales y en los monumentos que se hicieron en su nombre, pero al mismo tiempo, de manera paralela, iba cayendo su imagen por fuera del mundo castrense.

Con el comienzo de los estudios sistemáticos sobre el papel de los militares en Colombia, la guerra de Corea comenzó a ser evaluada desde las nuevas perspectivas teóricas que se incorporaban al saber de la academia. En un primer momento, el soldado fue invisibilizado como actor y convertido en un sujeto que dependía totalmente de la estructura de la institución militar, al punto de que se veía su papel simplemente como un agente del orden, en sentido genérico, para diferenciarse de la visión de orden que buscaban tanto Rojas Pinilla como Gómez. Otros trabajos produjeron una narrativa en la que los soldados se convirtieron en víctimas de las interacciones políticas y partidistas de los años cincuenta. Si bien adquirieron una mayor voz en autores como Kyong y Skladowska a partir de la década de 1990, el soldado seguía apareciendo como un sujeto sin agencia y sin facultades de acción propia, ya no en el Ejército, sino dentro de la sociedad. Ya no era la estructura del Ejército la que lo dominaba, sino la política partidista del presidente Laureano Gómez. 
La decadencia narrativa del soldado aparecería especialmente dentro de la literatura. La novela Mambrú y la obra teatral Guadalupe años sin cuenta reforzarían el estigma del soldado coreano como producto de la lucha política en Colombia. Sin embargo, este soldado ya no es homogéneo, como se veía en otros relatos, sino que se transforma y cambia según su historia de vida: es uno antes, campesino e inocente, y otro luego, producto de la guerra, más servil. Allí se muestra una mayor diferenciación entre el soldado raso y los oficiales, que los otros relatos no habían estimado, en su visión monolítica de las unidades que conforman un ejército.

Los mismos soldados salieron al paso ante estas representaciones que consideraban injustas, proponiendo una lectura de la guerra donde ellos tenían un papel más protagónico. Este sería el renacimiento de la narrativa, como respuesta a lecturas que los consideraban simple "carne de cañón”. Estos soldados presentan una visión de la historia donde se rompe la jerarquía militar y se transforman en los protagonistas de la historia. La composición del relato hizo que su narración fuera cambiante, según las circunstancias de su presente, pasando de ser una gesta memorable y traumática en los primeros a convertirse en un discurso político que reivindicaba unos derechos legales a una pensión digna, negada durante décadas por el Estado.

Michel-Rolph Trouillot sostiene que dentro de la creación de la historia hay una fuerte relación entre los procesos históricos y las narrativas. ${ }^{1}$ Los procesos históricos de

1 Michel-Rolph Trouillot. Silencing the Past, 23. 
la Violencia de Colombia tuvieron incidencia dentro de la creación de las narrativas históricas. Para la academia significó un nuevo interés por comprender el papel de las Fuerzas Armadas en la construcción del Estado. Esta narrativa, interesada especialmente en la historia política e institucional, se consolidó y ha dominado la forma de escribir y entender la guerra de Corea desde el ámbito académico. Gonzalo Sánchez considera, hablando sobre la memoria de La Violencia, que "los dueños del nuevo orden del Frente Nacional (contexto en el que surgieron estos primeros estudios sobre Corea), con su pretensión de refundación política, se reservan el control de la verdad sobre el pasado".

Los únicos actores institucionales que construyeron un relato sobre la guerra de Corea fueron los militares. No hay ningún registro en museos, ni en memoriales, ni fechas de conmemoración fuera del Ejército, el Ministerio de Defensa o la Naval. Fuera de estas puertas, en los lugares públicos, el Estado no se preocupó por honrar la memoria de los veteranos de esta guerra. Pareciera que desde el Frente Nacional existiera una política de olvido del pasado militar por parte del Estado, en especial los años de dictadura, con el fin de ejercer una buena memoria. ${ }^{3}$ Fuera del control estatal de la

2 Gonzalo Sánchez. Guerras, memoria e historia, 83.

3 Richard Vinyes (Ed.). El Estado y la memoria: gobiernos y ciudadanos frente a los traumas de la historia. Barcelona: RBA Libros, 2009, 25. "El Estado tiene una sola memoria, la 'buena memoria'. Dese su inicio democrático, el Estado ha ido constituyendo una economía moral, es decir, una administración de los bienes morales y simbólicos, datos y fechas, actos de Estado y recursos administrativos y de difusión diversísimos, que aparentemente - y solo aparentemente - están destinados a garantizar la inhibición de los conflictos de la memoria; inhibición 
memoria de la guerra se produjeron las diversas narraciones estudiadas aquí, las cuales se pueden dividir en dos grupos: una leyenda blanca de la participación, que se expresa en los escritos de la prensa conservadora, la música de los años cincuenta, las memorias de los oficiales (en especial Francisco Caicedo) y en algunos autores académicos como Saúl Rodríguez o Bradley Lynn Coleman, que señalan lo positivo de la participación en la modernización del Ejército; o la visión pesimista, la leyenda negra, producida desde sectores liberales, se extiende en la literatura y aparece en la mayoría de las obras académicas (Bermúdez Rossi, Carlos Urán, Elsa Blair, Adolfo Atehortúa, Bárbara Skladowska, etc.), donde se adopta una postura crítica frente al envío de tropas. Sin embargo, algunos aspectos de estas leyendas se intersectan, como los relatos de oficiales liberales como Álvaro Valencia Tovar o Gabriel Puyana García, que apoyan el argumento de que a la guerra fueron enviados muchos oficiales de su partido. Otras visiones simplemente pasan por alto el papel de los combatientes. Así, las visiones de la historia se van forjando de manera paralela, de forma que unos relatos se cruzan con otros como parte de la dinámica de la construcción de la historia.

¿Qué nos queda de los soldados rasos colombianos que participaron en la guerra de Corea? Estas visiones disímiles esconden una dimensión compleja sobre quiénes fueron los más de 3000 combatientes, en su mayoría campesinos, en una

considerara por la Administración como un deber moral para la buena convivencia de los ciudadanos de nuestra sociedad”. 
tierra desconocida para ellos. Esta investigación mostró que son más que las simples cifras que plasmaban los comandantes del Batallón Colombia y que tienen un papel más activo que el que mostraba la tradición académica. No son tampoco los héroes mitificados de los oficiales que sirven de modelo a seguir para los demás hombres que ingresen al Ejército, ni las meras víctimas de decisiones políticas ajenas que los arrojaron a un destino cruel. Fue un grupo heterogéneo de hombres que forjaron su propio destino, no solo en esos años de incertidumbre, sino en los siguientes sesenta años: la forma en que reconstruyeron su participación muestra cómo los sectores subalternos producen estrategias narrativas para luchar contra los discursos hegemónicos. El lector se queda con diferentes imágenes del soldado raso. ¿Cuál es la más cercana a la realidad? ¿Acaso una fuente diferente, como un registro de la lista de ingreso o una hoja de vida, nos permitiría comprender de manera indistinta quién es ese soldado raso que se ha dibujado en esta investigación?

Este trabajo tiene como objetivo generar una reflexión sobre cómo el conocimiento histórico es producido y comprender de manera más amplia el proceso de producción, desde la creación hasta la consolidación del relato histórico. La meta propuesta fue entender cómo la formación de la trama está ligada a un contexto de producción, y es un proceso tanto social como individual. Este trabajo no defiende un relativismo irresponsable en el discurso histórico, sino que busca comprender a través de un análisis estructurado cómo se produce el saber histórico, en este caso, del soldado raso que combatió en Corea. Al mismo tiempo, muestra cómo los 
individuos subalternos - en este caso los soldados - tratan de escapar de los relatos históricos dominantes mediante estrategias narrativas y presentan una versión de su historia que los reivindica y los reinventa como protagonistas de una realidad que buscan describir. 